and fear-based concerns of policy makers and the media who want us to 'move into the community', while simultaneously guaranteeing that adverse outcomes will not occur.

1 Forbes NF, Cash HT, Lawrie SM. Intensive home treatment, admission rates and use of mental health legislation. Psychiatrist 2010; 34: $522-4$

2 Middleton $\mathrm{H}$, Glover G, Onyett S, Linde K. Crisis resolution/home treatment teams, gate-keeping and the role of the consultant psychiatrist. Psychiatr Bull 2008; 32: 378-9.

3 Care Quality Commission. Monitoring the Use of the Mental Health Act in 2009-10. Care Quality Commission, 2010.

Philip McGarry and Ashling O'Hare are consultant psychiatrists in home treatment and Ciaran McNally is specialty trainee (ST6), Belfast Health and Social Care Trust, Belfast, UK, email: McGarry.philipj@ belfasttrust.hscni.net

doi: $10.1192 /$ pb.35.4.155a

The increase in compulsory treatment following introduction of a crisis resolution service as observed by Forbes et al was to be entirely expected as other studies have mentioned this association before. ${ }^{2,3}$ However, I am a bit puzzled about the explanation the authors provided regarding this finding - the team probably having a low threshold for accepting risk and being more likely to consider the use of the Mental Health Act. I certainly do not believe this to be an explanation that would ring true with other crisis teams, for I am under the impression that the staff in most crisis teams have a very high threshold for admitting someone; this is, I think, to do with their role of gatekeeping admissions (and controlling the beds).

The other important aspect that needs to be considered here relates to the fact that the team in the study do not have control over admissions under the Mental Health Act outside working hours, which are between $8 \mathrm{am}$ and $12 \mathrm{pm}$. It would be useful to see the numbers of people admitted under the Act out of hours, who were being assessed by other professionals undertaking their own risk assessments. It should also be remembered that many patients assessed and admitted under the Mental Health Act during working hours are not always assessed by the crisis team; community mental health teams undertake their own Mental Health Act assessments.

Finally, let us consider the staffing levels within the crisis team: one part-time staff grade psychiatrist but no dedicated consultant. This in itself may explain the fact that the team has to rely heavily upon others to undertake assessments. Once professionals outside the crisis team make a decision to detain someone there is nothing that the crisis team can do about it; they simply have to find a bed for the detained person.

1 Forbes NF, Cash HT, Lawrie SM. Intensive home treatment, admission rates and use of mental health legislation. Psychiatrist 2010; 34: 522-4.

2 Keown P, Tacchi MJ, Niemiec S, Hughes J. Changes to mental healthcare for working age adults: impact of a crisis team and an assertive outreach team. Psychiatr Bull 2007; 31: 288-92.

3 Tyrer P, Gordon F, Nourmand S, Lawrence M, Curran C, Southgate D, et al. Controlled comparison of two crisis resolution and home treatment teams. Psychiatrist 2010; 34: 50-4.

Mohinder Kapoor is specialty registrar (ST5) in old age psychiatry, South West Yorkshire Partnership NHS Foundation Trust, Beckside Court, 286 Bradford Road, Batley WF17 5PW, UK, email: moe.kapoor@nhs.net

doi: $10.1192 / p b .35 .4 .156$

\section{Age discrimination across the lifespan}

Many of Anderson's observations ${ }^{1}$ on unjustified age discrimination at the later stages of the lifespan apply also to children and adolescents with mental health problems. They receive a disproportionately low level of funding, are excluded from much research, are subject to often inappropriate extrapolation of treatment guidelines for adults, and until recently have been excluded from formal mental health strategic thinking (both the National Service Framework ${ }^{2}$ and New Horizons ${ }^{3}$ specifically excluded child and adolescent mental health services (CAMHS) from their remits).

Anderson states that the Royal College of Psychiatrists' position statement on age discrimination in mental health ${ }^{4}$ incorporated contributions from all of its constituent faculties and sections. It is unclear to me where the contribution from the Child and Adolescent Psychiatry Faculty is to be found. In this regard, the government's new mental health strategy ${ }^{5}$ is to be welcomed as it adopts an all-age approach to mental health by explicitly including CAMHS within it. Strategies aimed at addressing age discrimination need to consider the whole of the lifespan if they are not unwittingly to recreate it.

1 Anderson D. Age discrimination in mental health services needs to be understood. Psychiatrist 2011; 35: 1-4.

2 Department of Health. National Service Framework for Mental Health Modern Standards and Service Models. Department of Health, 1999.

3 Department of Health. New Horizons: A Shared Vision for Mental Health. Department of Health, 2009.

4 Royal College of Psychiatrists. Age Discrimination in Mental Health Services: Making Equality a Reality (Position Statement PS2/2009). Royal College of Psychiatrists, 2009.

5 Department of Health. No Health without Mental Health: A CrossGovernment Mental Health Outcomes Strategy for People of All Ages. Department of Health, 2011.

Andrew F. Clark, consultant in adolescent psychiatry, Greater Manchester West Mental Health NHS Foundation Trust, Manchester, UK, email: andrew.clark@gmw.nhs.uk

doi: $10.1192 / p b .35 .4 .156 a$

\section{No physical health, only mental health}

In the canteen of our psychiatric hospital I found myself standing behind an in-patient who had been escorted by a nurse from the ward. I was rather concerned to witness the patient request, and be sold, three hot dinners, three sandwiches, four packets of crisps and four bottles of an energy drink. The nurse escorting the patient confirmed that all the food was indeed for the patient himself and that he did this every day, which was also confirmed by the patient's obesity. I expressed my concern that the patient was putting his health at risk by being allowed to buy and eat so much food in the hospital. The reply given by the nurse was that the treatment team were all aware of the situation but were of the opinion that 'Well, what can we do, the patient has rights to eat what he wants, who are we to stop him?' Those responsible for the care and treatment of the patient (detained under the Mental Health Act) were aware of his extreme overeating but they were merely observing such behaviour, believing themselves to be attending to his mental health needs in isolation, even to the extent of escorting the patient on his bingeing trips. 
We are all aware of the possible risks of metabolic syndrome associated with many of the physical interventions we prescribe, but awareness alone is of little help to our patients. The motto of the Royal College of Psychiatrist is 'No health without mental health', but we appear to be at risk of following an alternative motto, 'No physical health, only mental health'. I would welcome some advice from the College or the thoughts of other members who have been able to implement a more useful response to the observed problem in their own clinical institutions.

Az Hakeem, MBBS MSc FRCPsych, Consultant Psychiatrist, Camden and Islington NHS Foundation Trust, London, UK, email: az@drazhakeem.com doi: $10.1192 / \mathrm{pb} .35 .4 .156 \mathrm{~b}$

\section{Bored and stressed in-patients smoke more}

Similarly to Thakkar et $a l,{ }^{1}$ we carried out a survey enquiring about the smoking habits of in-patients on the general adult wards of a psychiatric hospital (in York) before the hospital closed each ward's smoking room. ${ }^{2}$ We too were concerned to discover that the majority of patients (56\%) smoked and that the majority of these (63\%) reported smoking more after admission than in the week before. In keeping with Thakkar et al's findings, we discovered that the main reason given for smoking more was boredom, with other key reasons being stress and the wish to socialise.

Rather more heartening was our finding that $17 \%$ of the smokers surveyed reported smoking less after admission, citing improvement in mental state and a dislike of the smoking areas as the main reasons. Unlike in Thakkar et al's survey, our in-patients did not think their smoking habits had changed because of medication side-effects.

We also felt that the issue of in-patient boredom should be addressed through active management of the ward environment and that our services should be better advocates of smoking cessation. There is the hope that the recent smoke-free legislation will lead to substantially lowered tobacco consumption in the general population. If so, it will become more important than ever for psychiatric wards to be activity-focused places. Some hospitals have improved the ward environment through hard work and investment. If such change for the better is not widespread then the physical health of people with mental illness who require hospital care - but experience it in a tedious, activity-free ward environment that finds them increasing their smoking habit - will drift further than ever from that of the rest of the population.

1 Thakkar PB, Garcia J, Burton L. Smoking and people with mental illness Psychiatrist 2011; 35: 30.

2 Ker S, Owens D. Admission to a psychiatric unit and changes in tobacco smoking. Clin Pract Epidemiol Ment Health 2008; 4: 12.

Suzy Ker, consultant psychiatrist, Harrogate District Hospital, Harrogate, UK, email: s.ker@nyypct.nhs.uk, David Owens, senior lecturer, Leeds Institute of Health Sciences, University of Leeds, UK.

doi: $10.1192 / p b .35 .4 .157$ 